\title{
Synthesis and Characterization of All Renewable Resources Based Branched Polyester: Poly(2,5-furandicarboxylic acid-co-glycerol)
}

\author{
Ananda S. Amarasekara, Ashfaqur Razzaq, and Paul Bonham \\ Department of Chemistry, Prairie View A\&M University, Prairie View, TX 77446, USA \\ Correspondence should be addressed to Ananda S. Amarasekara; asamarasekara@pvamu.edu
}

Received 21 May 2013; Accepted 20 June 2013

Academic Editors: T. R. Chantara, S.-H. Jafari, and S. Yamazaki

Copyright (C) 2013 Ananda S. Amarasekara et al. This is an open access article distributed under the Creative Commons Attribution License, which permits unrestricted use, distribution, and reproduction in any medium, provided the original work is properly cited.

Condensation of all renewable resources based monomers 2,5-furandicarboxylic acid and glycerol in the presence of $2 \mathrm{~mol}_{0} \mathrm{Sb}_{2} \mathrm{O}_{3}$ catalyst at $210^{\circ} \mathrm{C}$ gives a branched polyester resin in $70 \%$ yield. This resin was characterized by elemental analysis, ${ }^{1} \mathrm{H},{ }^{13} \mathrm{C}$ NMR, FT-IR, and TGA-DTG.

\section{Introduction}

The growing concern about declining fossil fuel reserves has stimulated recent interests in explorations for renewable resources based fuels as well as platform chemicals for the chemical and polymer industries. Furan compounds derived from renewable carbohydrates are a major class in this new generation of platform chemicals, and 2,5-furandicarboxylic acid (FDCA, 1) (Figure 1) is a particularly interesting compound in this group [1-3]. 2,5-Furandicarboxylic acid is the symmetrical diacid resulting from the oxidations of both primary alcohol and aldehyde groups of 5-hydroxymethylfurfural (HMF) [4] to carboxylic acid groups. This is probably the most important derivative of HMF; this symmetrical aromatic diacid has been looked as a potential replacement and the renewable resources based equivalent of terephthalic acid [5], which is a monomer in polyethylene terephthalate (PET) plastics. Furthermore, FDCA is listed in a 2004 US Department of Energy National Renewable Energy Laboratory (NREL) report [6] as one of the twelve building blocks that can be subsequently converted to a number of highvalue bio-based chemicals or materials. There are a number of recent reports on the use of FDCA for the preparation of linear polyesters $[1,7]$ using a variety of polyesterification techniques. The widely used methods involve the use of 2,5-furandicarboxylic acid dichloride, trans-esterification, and interfacial polycondensation $[7,8]$. The most commonly studied diol is the ethylene diol $[5,7,8]$, but linear polyesters have been prepared by using a number of other diols like 1,3-propane diol [7], 1,4-butane diol [9], 1,6-hexane diol [9], 1,8-octane diol [9], D-isosorbide [10], D-isoidide [10], bis(2,5hydroxymethyl)-furan [7], bis-(1,4-hydroxymethyl) benzene [7], and hydroquinone [7] as well. The polyester prepared using ethylene diol is probably the most appealing, and Gandini et al. have shown that this renewable resources based equivalent of PET has many properties comparable with PET [5].

2,5-Furandicarboxylic acid (1) can be prepared by oxidation of 5-hydroxymethylfurfural (HMF) with some common stoichiometric oxidation reagents $[1,4]$. Then, there are a number of reports [1] on catalytic oxidation methods for the conversion of HMF to FDCA, using noble metal catalysts. Excellent yields are reported in the use of $\mathrm{Pt}-\mathrm{Pb} / \mathrm{C}$ catalyst in alkaline aqueous medium, using molecular oxygen as the primary oxidant [11]. Another approach to FDCA is the direct dehydration of mucic acid, under strongly acidic conditions using sulfuric [12] or p-toluenesulfonic acid [13] as the acid catalyst. In our experiments we have prepared FDCA by simple dehydration of mucic acid using $48 \%$ aqueous $\mathrm{HBr}$ as the catalyst and the solvent.

Glycerol (GL, 2) (Figure 1) is another renewable resource based platform chemical formed in the saponification of 


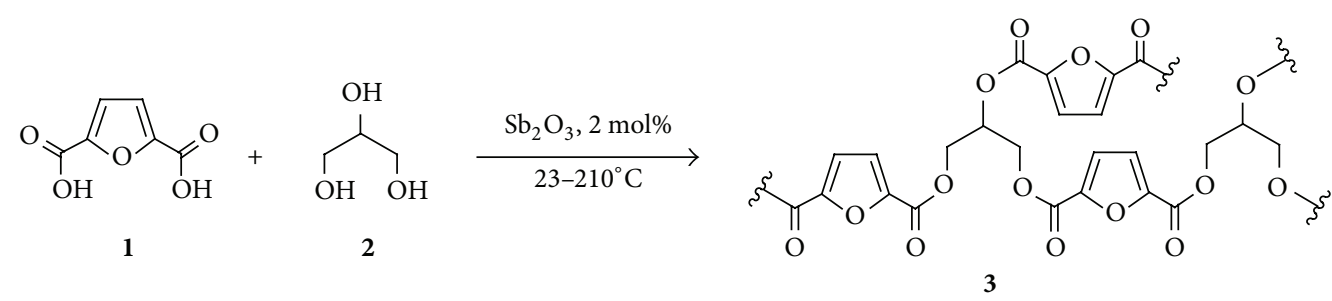

FIGURE 1: Synthesis of poly(2,5-furandicarboxylic acid-co-glycerol) (3).

triglycerides in vegetable oils and a byproduct of soap making and biodiesel production. Present interest in the biomassderived feed stock chemicals has initiated an array of research efforts in converting glycerol to monomers such as propylene glycol, acrolein, and epichlorohydrin that can be used with the existing polymerization technologies. Additionally, there are a number of new reports on the development of novel polymeric materials using glycerol directly as one of the monomers [14-17]. For example, glycerol has been used as a monomer in the polymerizations with adipic and oleic diacid using immobilized Candida antarctica Lipase B (Novozym 435) as a biocatalyst [17]. In another example, Luman et al. reported [18] the preparation of dendritic polymers composed of glycerol and succinic acid for new medical applications. In addition, we have recently shown [19] that glycerol can be directly condensed with another renewable resources based material, levulinic acid, to prepare an oligoketal-ester, oligo (levulinic acid-co-glycerol) [19].

Our interests $[19,20]$ in this field of preparation and characterization of novel polymeric materials from renewable feed stocks led us to study the condensation of FDCA with polyols to make branched furanic polyesters. In this communication, we report the first synthesis and characterization of a branched furanic polyester resin by solvent free condensation of FDCA with glycerol.

\section{Experimental}

2.1. Materials and Physical Measurements. Mucic acid, glycerol, antimony (III) oxide (>99\%), and $48 \% \mathrm{HBr}$ were purchased from Aldrich Chemical Co. ${ }^{1} \mathrm{H}$ NMR spectra were recorded in DMSO- $d_{6}$ or $\mathrm{CF}_{3} \mathrm{COOD}$ on a Varian Mercury plus spectrometer operating at $400 \mathrm{MHz}$, and chemical shifts are given in ppm downfield from TMS $(\delta=0.00) .{ }^{13} \mathrm{C}$ NMR spectra in DMSO- $d_{6}$ or $\mathrm{CF}_{3} \mathrm{COOD}$ were recorded on the same spectrometer operating at $100 \mathrm{MHz}$; chemical shifts were measured relative to DMSO- $d_{6}$ and converted to $\delta($ TMS $)$ using $\delta(\mathrm{DMSO})=39.51$ and $\delta\left(\mathrm{CF}_{3^{-}}\right)=116.60 \mathrm{ppm}$. FT-IR spectra were recorded on a Thermo Nicolet IR 200 spectrometer using $\mathrm{KBr}$ pellets. Thermogravimetric analysis was carried out in air on a Perkin Elmer Diamond TG/DTG system at a heating rate $10^{\circ} \mathrm{C} / \mathrm{min}$. Elemental analysis was performed at QTI laboratories, NJ, USA.

2.2. Synthesis of 2,5-Furandicarboxylic Acid (FDCA) (1). A suspension of mucic acid (5.0 g, $24 \mathrm{mmol}$ ) in $35 \mathrm{~mL}$ of $48 \%$ aq. $\mathrm{HBr}$ was refluxed for $18 \mathrm{~h}$. Then the reaction mixture was distilled to remove $\sim 25 \mathrm{~mL}$ of aq. $\mathrm{HBr}$. The resulting dark suspension was cooled in an ice bath and basified by careful addition of $4 \mathrm{M}$ aq. sodium hydroxide solution. This basic solution was filtered using a Buchner funnel to remove charred byproducts, and the filtrate was acidified to $\mathrm{pH}=1$ by addition of conc. $\mathrm{HCl}$ and kept in a refrigerator overnight for crystallization. The solid product formed was collected by suction filtration and dried in air to give pure 2,5furandicarboxylic acid (FDCA) (1) as white crystals (1.80 g, $48 \%$ yield), m.pt. $>300^{\circ} \mathrm{C} .{ }^{1} \mathrm{H}$ NMR of the product indicated that sample is $>99.5 \%$ pure.

${ }^{1} \mathrm{H}$ NMR (DMSO- $\left.d_{6}\right) \delta 3.20-3.90(\mathrm{~b}, 2 \mathrm{H}), 7.27$ (s, 2H). ${ }^{13} \mathrm{C}$ NMR (DMSO- $\left.d_{6}\right) \delta 118.9,147.5,159.4$.

2.3. Synthesis of Poly(2,5-furandicarboxylic acid-co-glycerol) (3). A mixture of 2,5-furandicarboxylic acid (407 mg, $2.61 \mathrm{mmol})$ and glycerol (160 mg, $1.74 \mathrm{mmol}$ ) was dissolved in $1.0 \mathrm{~mL}$ of $N, N$-dimethyl formamide in a small round bottom flask, then $\mathrm{Sb}_{2} \mathrm{O}_{3}$ (15.2 $\mathrm{mg}, 0.068 \mathrm{mmol}, 2 \mathrm{~mol} \%$ ) was added to this solution. The resulting mixture was gradually heated from room temperature $\left(23^{\circ} \mathrm{C}\right)$ to $150^{\circ} \mathrm{C}$ under a nitrogen atmosphere during a period of $1.0 \mathrm{~h}$ and held at $150^{\circ} \mathrm{C}$ for $30 \mathrm{~min}$ then the reaction flask was connected to a vacuum $(5 \mathrm{mmHg})$ and heated to $210^{\circ} \mathrm{C}$, in $30 \mathrm{~min}$. and held at $210^{\circ} \mathrm{C}$ for $2 \mathrm{~h}$ under vacuum. Flask was cooled, and the solid product was washed with hot methanol in a soxhlet extractor for $16 \mathrm{~h}$ then dried under vacuum to yield poly(2,5-furandicarboxylic acid-co-glycerol) as a white sold. The experiment was carried out in triplicate; average product weight: $331 \mathrm{mg}$, 70\% yield.

Anal. Calc. for $\mathrm{C}_{24} \mathrm{H}_{16} \mathrm{O}_{15}$ : C, 52.95; H, 2.96. Found: C, 53.31; H, 2.73.

${ }^{1} \mathrm{H},{ }^{13} \mathrm{C}$ NMR, and FT-IR are shown in Figures 2(a), 2(b), and 3 , respectively.

Thermal analysis recorded in the $20-800^{\circ} \mathrm{C}$ temperature range in air using a $\mathrm{Pt}$ crucible showed a two step thermogravimetric (TG) analysis curve with 78 and $22 \%$ weight losses (Figure 4). These weight losses correspond to two peaks at 355 and $590^{\circ} \mathrm{C}$ in the derivative TG analysis (DTG) plot.

\section{Results and Discussion}

3.1. Synthesis and Characterization of 2,5-Furandicarboxylic Acid (FDCA) (1). 2,5-Furandicarboxylic acid used for the polymer synthesis was prepared by dehydration of mucic acid by refluxing in $48 \% \mathrm{HBr}$ for $18 \mathrm{~h}$. We have observed that shorter reaction periods give lower yields, whereas reaction 


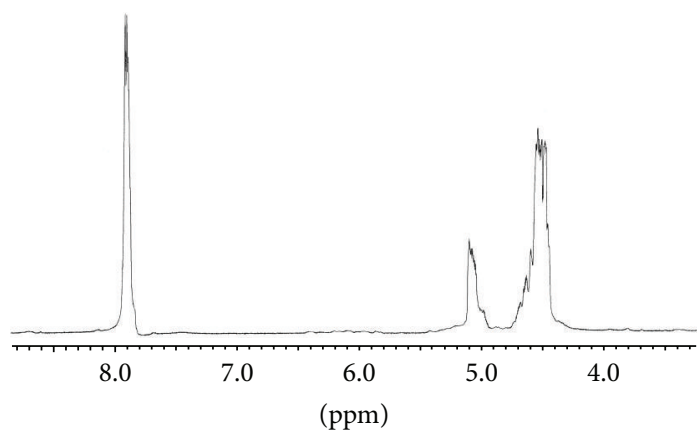

(a)

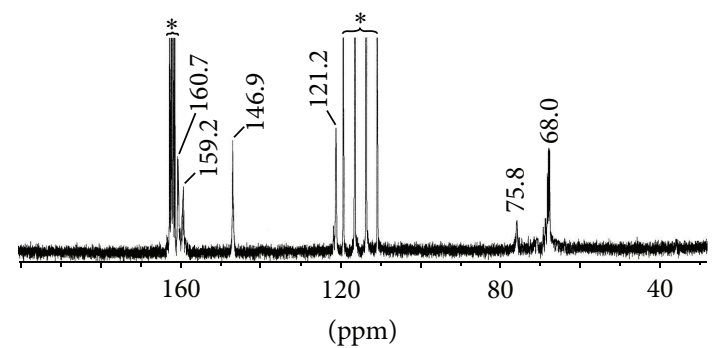

(b)

Figure 2: ${ }^{1} \mathrm{H}$ (a) and ${ }^{13} \mathrm{C}$ (b) NMR spectra of poly(2,5-furandicarboxylic acid-co-glycerol) (3) in $\mathrm{CF}_{3} \mathrm{COOD}$, ${ }^{*}$ solvent.

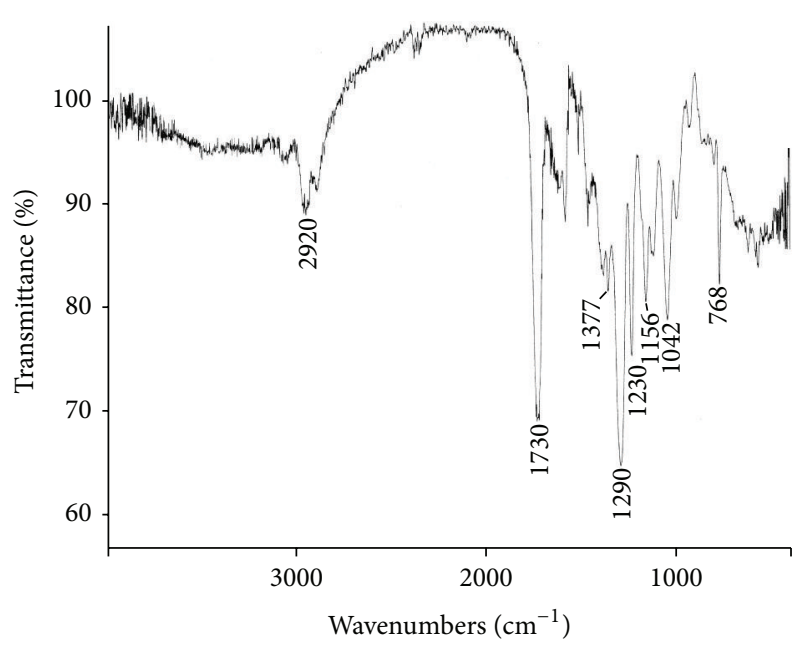

FIGURE 3: FT-IR spectrum of poly(2,5-furandicarboxylic acid-coglycerol) (3).

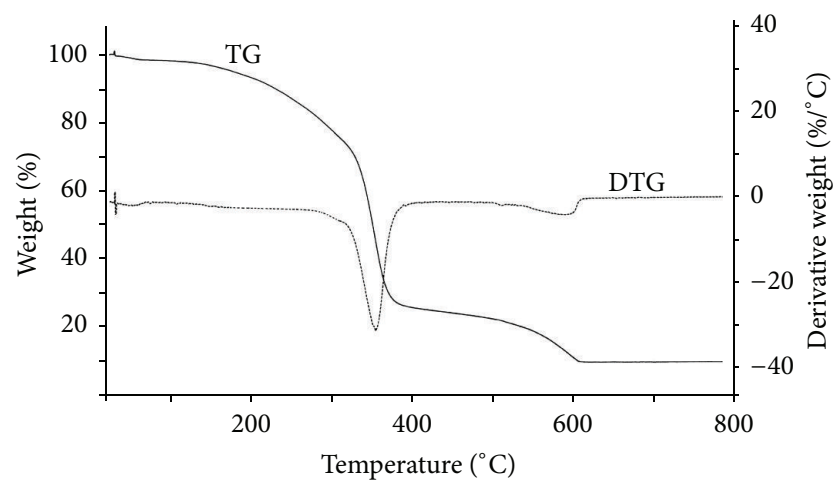

FIGURE 4: TG-DTG Curves of poly(2,5-furandicarboxylic acid-coglycerol) (3).

periods longer than $18 \mathrm{~h}$ produce excessive charring of the reaction mixture. Furthermore, we have found that it is essential to convert the product to its disodium salt form before the removal of the charred byproducts by filtration. This method provides a simple direct route to FDCA, when compared to the conventional methods $[1,4]$ of oxidation of 5-hydroxymethylfurfural. The ${ }^{1} \mathrm{H}$ and ${ }^{13} \mathrm{C}$ NMR spectra of the product are in agreement with the reported data [13] for FDCA.

3.2. Synthesis and Characterization of Poly(2,5-furandicarboxylic acid-co-glycerol) (3). poly(2,5-furandicarboxylic acid-co-glycerol) (3) was prepared using FDCA:GL 3:2 molar ratio as shown in Figure 1. The polymer resin 3 is insoluble in water and all the common organic solvents, including DMF, DMSO, and only slightly soluble in trifluoroacetic acid. These solubility properties are similar to the FDCA-ethylene glycol linear polyester reported in the literature [5].

Proton NMR of the polymer resin 3, recorded in $\mathrm{CF}_{3} \mathrm{COOD}$, is shown in Figure 2(a). This spectrum showed a complex multiplet in the 4.40-5.22 ppm region for the glycerol unit hydrogens and a broad singlet at $7.92 \mathrm{ppm}$ for C-3,4 furan ring hydrogens. ${ }^{13} \mathrm{C}$ NMR (Figure $2(\mathrm{~b})$ ) spectrum was recorded in $\mathrm{CF}_{3} \mathrm{COOD}$ using a $5 \mathrm{~s}$ relaxation delay, and this spectrum showed glycerol unit carbons at 68.0 and $75.8 \mathrm{ppm}$. The ${ }^{13} \mathrm{C}$ peak at $121.2 \mathrm{ppm}$ was assigned to $\mathrm{C}-3,4$ carbons, whereas 146.9 ppm was assigned to C-2,5 carbons of the furan ring. These values are comparable to the corresponding ${ }^{13} \mathrm{C}$ resonances reported [5] for poly(ethylene 2,5-furandicarboxylate) at 121.1 and $147.1 \mathrm{ppm}$. The two resonances at 159.2 and $160.7 \mathrm{ppm}$ were assigned to two types of ester carbonyls in the polymer, resulting from esterification at primary and secondary -OH groups of glycerol. Furthermore, these ester carbonyl peaks are comparable to single ester carbonyl resonance reported at $161.0 \mathrm{ppm}$ for poly(ethylene 2,5-furandicarboxylate) [5].

FT-IR spectrum of the polymer resin 3 recorded in $\mathrm{KBr}$ disk (Figure 3) showed characteristic ester bands at $1730 \mathrm{~cm}^{-1}$ for $\mathrm{C}=\mathrm{O}, 1290 \mathrm{~cm}^{-1}$ for $\mathrm{C}-\mathrm{O}-\mathrm{C}$, and similar absorptions are known for furanic polyesters reported in the literature [7]. Additionally the sharp IR absorption at $768 \mathrm{~cm}^{-1}$ can be assigned to the furan ring, further supporting the proposed structure 3 in Figure 1. Thermogravimetric-derivative thermogravimetric (TG-DTG) analysis curves of the polymer resin 3 showed that new material is stable up to about $275^{\circ} \mathrm{C}$ in air. Furthermore, polymer was found to degrade in two steps of 78 and $22 \%$ weight losses corresponding to peaks at 355 and $590^{\circ} \mathrm{C}$ in the DTG curve as shown in Figure 4. 


\section{Conclusion}

We have shown that condensation of all renewable resources based monomers 2,5-furandicarboxylic acid and glycerol in the presence of $2 \mathrm{~mol} \% \mathrm{Sb}_{2} \mathrm{O}_{3}$ catalyst at $210^{\circ} \mathrm{C}$ gives a branched polyester resin in $70 \%$ yield. This hard resin is insoluble in all common organic solvents and only slightly soluble in trifluoroacetic acid. 2,5-Furandicarboxylic acid monomer used in the polymer synthesis can be prepared in $48 \%$ yield in a single step by dehydration of mucic acid with $48 \% \mathrm{HBr}$.

\section{Conflict of Interests}

The authors do not have a direct financial relation with the commercial identities mentioned in this paper that might lead to a conflict of interests for any of the authors.

\section{Acknowledgments}

The authors would like to thank the American Chemical Society-PRF grant UR1-49436, NSF grant CBET-0929970, and USDA grant CBG-2010-38821-21569 for financial support.

\section{References}

[1] A. S. Amarasekara, "5-Hydroxymethylfurfural based polymers," in Renewable Polymers, V. Mittal, Ed., pp. 381-428, WileyScrivener, Salem, Mass, USA, 2011.

[2] M. N. Belgacem and A. Gandini, Monomers, Polymers and Composites from Renewable Resources, Elsevier, Amesterdam, The Netherlands, 2008.

[3] A. Gandini, "Polymers from renewable resources: a challenge for the future of macromolecular materials," Macromolecules, vol. 41, no. 24, pp. 9491-9504, 2008.

[4] J. Lewkowski, "Synthesis, chemistry and applications of 5hydroxymethyl-furfural and its derivatives," Arkivoc, vol. 2001, no. 1, pp. 17-54, 2001.

[5] A. Gandini, A. J. D. Silvestre, C. P. Neto, A. F. Sousa, and M. Gomes, "The furan counterpart of polyethylene terephthalate: an alternative material based on renewable resources," Journal of Polymer Science A, vol. 47, no. 1, pp. 295-298, 2009.

[6] T. Werpy and G. Peterson, "Top value added chemicals from biomass," no. DOE/GO-102004-1992, US Department of Energy, Office of Scientific and Technical Information, 2004, http://www.nrel.gov/docs/fy04osti/35523.pdf.

[7] M. Gomes, A. Gandini, A. J. D. Silvestre, and B. Reis, "Synthesis and characterization of poly(2,5-furan dicarboxylate)s based on a variety of diols," Journal of Polymer Science A, vol. 49, no. 17, pp. 3759-3768, 2011.

[8] J. A. Moore and J. E. Kelly, "Polyesters derived from furan and tetrahydrofuran nuclei," Macromolecules, vol. 11, no. 3, pp. 568$573,1978$.

[9] O. Grosshardt, U. Fehrenbacher, K. Kowollik, B. Tübke, N. Dingenouts, and M. Wilhelm, "Synthese und charakterisierung von polyestern und polyamiden auf der basis von furan-2, 5dicarbonsäure," Chemie-Ingenieur-Technik, vol. 81, no. 11, pp. 1829-1835, 2009.
[10] R. Storbeck and M. Ballauff, "Synthesis and properties of polyesters based on 2,5-furandicarboxylic acid and 1,4:3,6dianhydrohexitols," Polymer, vol. 34, no. 23, pp. 5003-5006, 1993.

[11] P. Verdeguer, N. Merat, and A. Gaset, "Oxydation catalytique du HMF en acide 2,5-furane dicarboxylique," Journal of Molecular Catalysis, vol. 85, no. 3, pp. 327-344, 1993.

[12] H. Muramatsu, "Synthesis of acetylenes containing heterocyclic ring," Kenkyu Hokoku-Asahi Garasu Zaidan, vol. 60, pp. 167174, 1992.

[13] J. Lewkowski, "Convenient synthesis of furan-2,5-dicarboxylic acid and its derivatives," Polish Journal of Chemistry, vol. 75, no. 12, pp. 1943-1946, 2001.

[14] H. Fu, A. S. Kulshrestha, W. Gao, R. A. Gross, M. Baiardo, and M. Scandola, "Physical characterization of sorbitol or glycerol containing aliphatic copolyesters synthesized by lipasecatalyzed polymerization," Macromolecules, vol. 36, no. 26, pp. 9804-9808, 2003.

[15] D. Pramanick and T. T. Ray, "Synthesis and biodegradation of copolyesters from citric acid and glycerol," Polymer Bulletin, vol. 19, no. 4, pp. 365-370, 1988.

[16] A. A. H. Kadhum, M. N. Baharu, and M. H. Mahmood, "Elastic polyesters from glycerol and azelaic acid," Advanced Materials Research, vol. 233-235, pp. 2571-2575, 2011.

[17] Y. Yang, W. Lu, J. Cai et al., "Poly(oleic diacid-co-glycerol): comparison of polymer structure resulting from chemical and lipase catalysis," Macromolecules, vol. 44, no. 7, pp. 1977-1985, 2011.

[18] N. R. Luman, T. Kim, and M. W. Grinstaff, "Dendritic polymers composed of glycerol and succinic acid: synthetic methodologies and medical applications," Pure and Applied Chemistry, vol. 76, no. 7-8, pp. 1375-1385, 2004.

[19] A. S. Amarasekara and S. A. Hawkins, "Synthesis of levulinic acid-glycerol ketal-ester oligomers and structural characterization using NMR spectroscopy," European Polymer Journal, vol. 47, no. 12, pp. 2451-2457, 2011.

[20] A. S. Amarasekara, D. Green, and L. D. Williams, "Renewable resources based polymers: synthesis and characterization of 2,5diformylfuran-urea resin," European Polymer Journal, vol. 45, no. 2, pp. 595-598, 2009. 

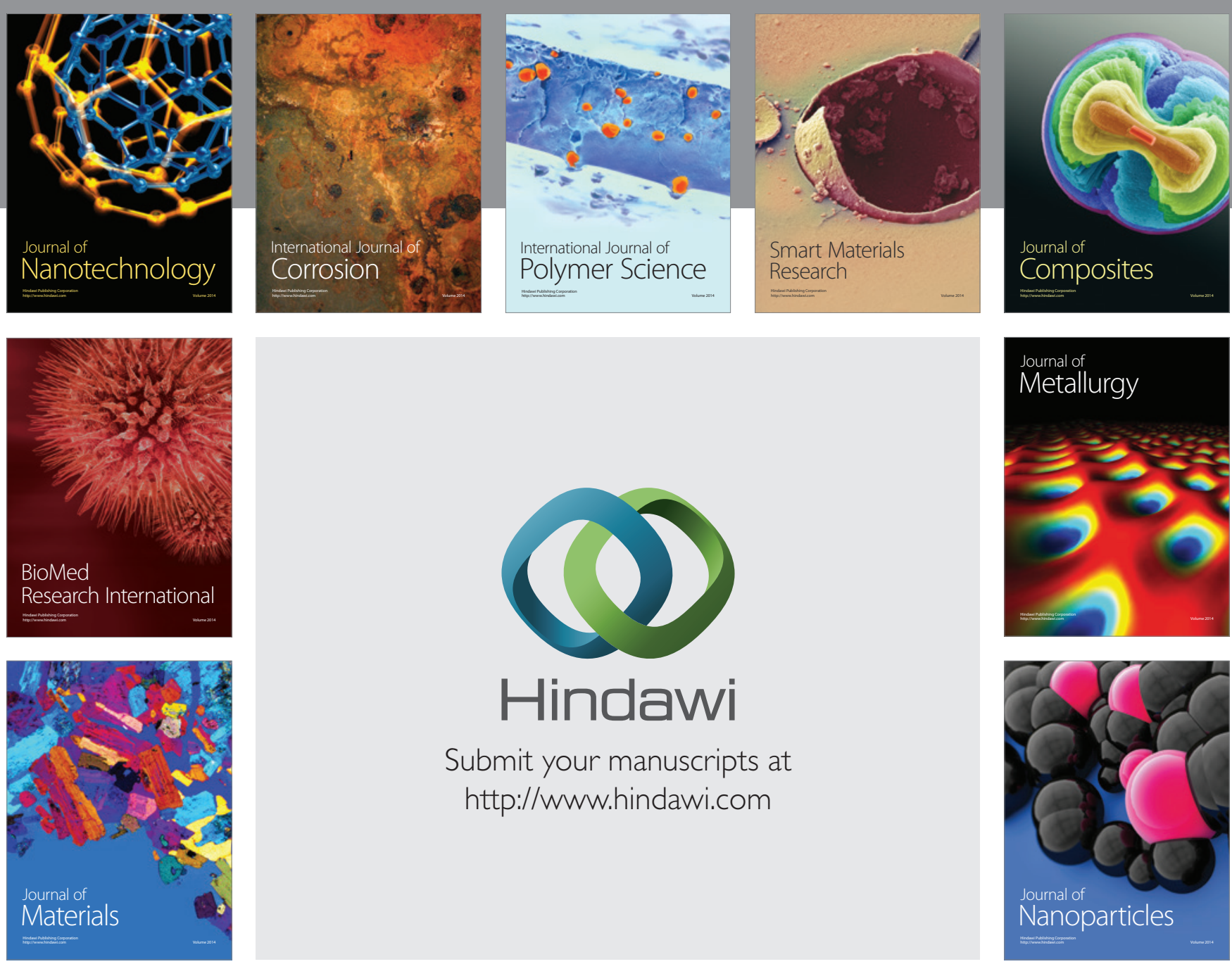

Submit your manuscripts at http://www.hindawi.com
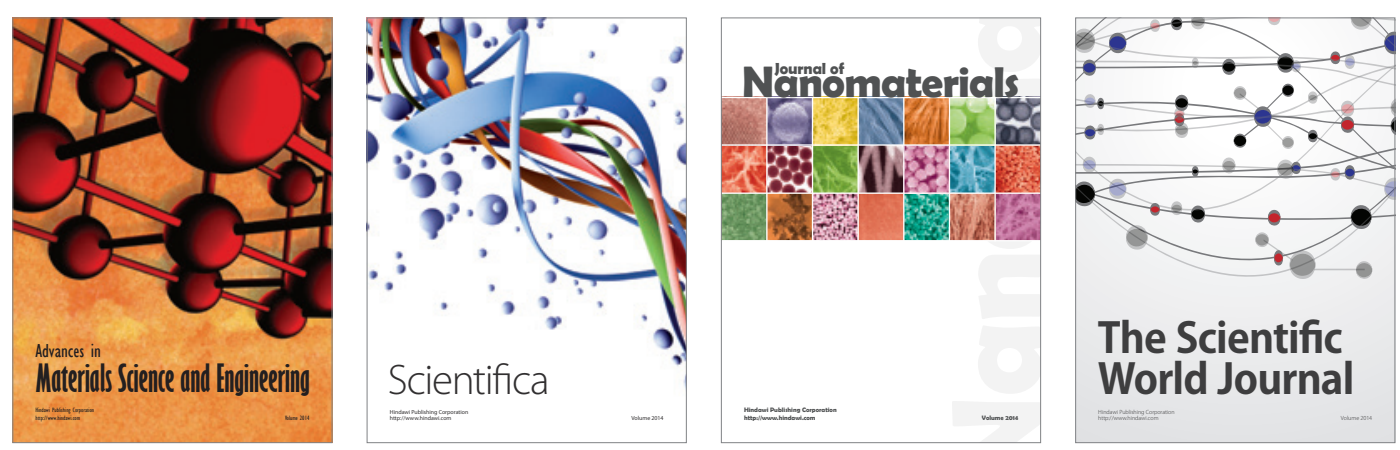

\section{The Scientific World Journal}
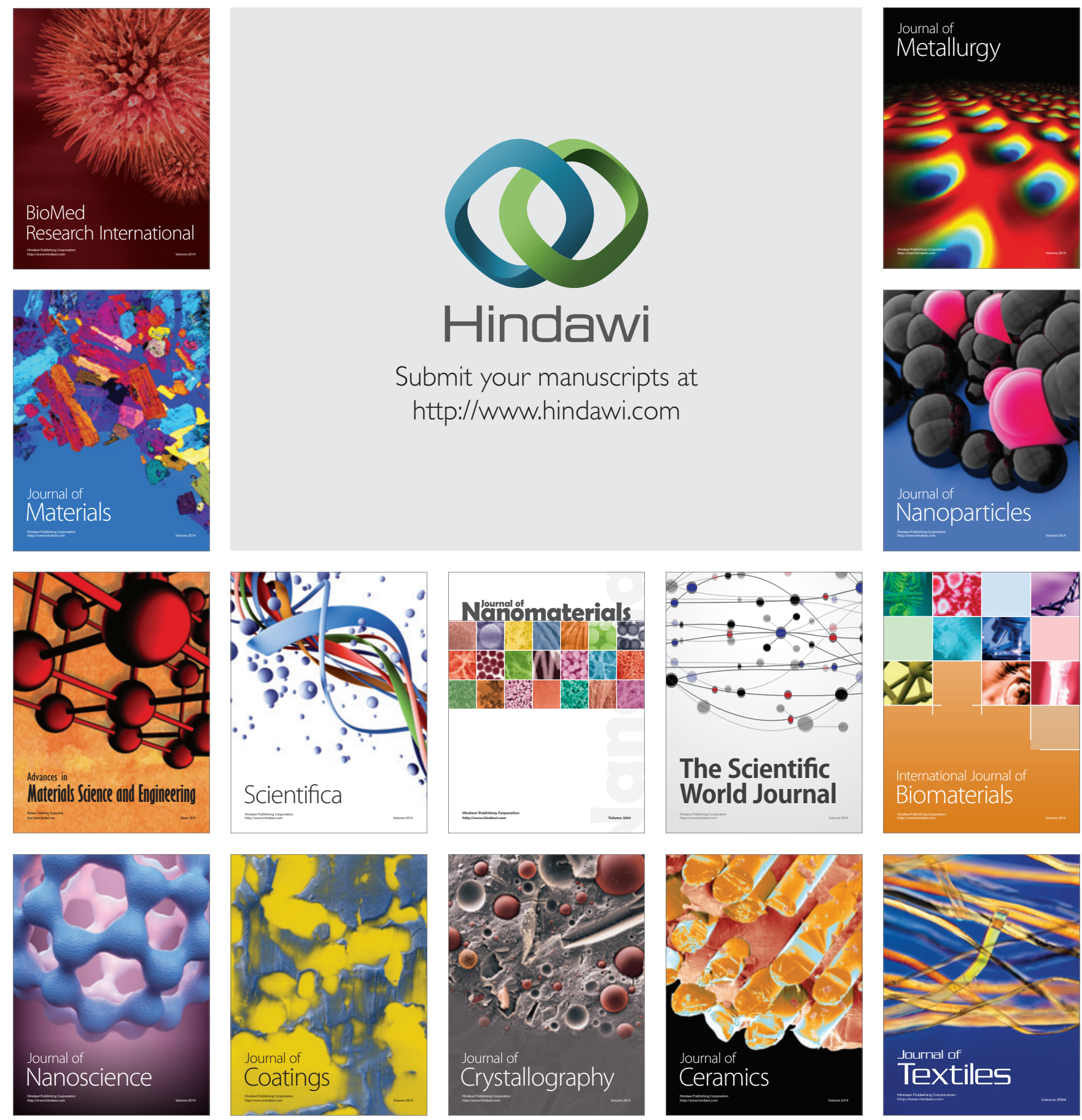